\title{
Symptomatic Epstein-Barr virus infection and multiple sclerosis
}

\author{
C N Martyn, M Cruddas, D A S Compston
}

\begin{abstract}
In a case-control study of 214 patients with multiple sclerosis, recall of infectious mononucleosis in subjects seropositive for Epstein-Barr viral capsid antigen was associated with a relative risk of 2.9 (95\% CI $1 \cdot 1$ to $7 \cdot 2)$. Those who reported having infectious mononucleosis before the age of 18 years had a relative risk of multiple sclerosis of $7.9(95 \%$ CI 1.7 to $37 \cdot 9)$. The pathogenesis of multiple sclerosis may involve an age-dependent host response to Epstein-Barr virus infection.
\end{abstract}

(F Neurol Neurosurg Psychiatry 1993;56:167-168)

The consequences of infection with EpsteinBarr virus depend on the age at which the virus is first encountered. Infection in infancy or matic but when exposure is delayed until adolescence or adult life, rates of clinical infectious mononucleosis approach $50 \% .^{12}$ Individuals who recall an episode of infectious mononucleosis are likely therefore to have first encountered Epstein-Barr virus sometime after the early years of childhood. A strong positive association between multiple sclerosis and recalled symptoms of infectious mononucleosis has recently been reported. ${ }^{3}$ This suggests that delayed first exposure to Epstein-Barr virus may be involved in the aetiology of demyelination. To investigate this association further, we have reanalysed serological data and information about age of infection that had been collected in a case-control study of viral infection in patients with multiple sclerosis carried out in London during the early 1980s.

MRC Environmental

Epidemiology Unit,

(University of

Southampton),

Southampton General

Hospital,

Southampton SO9

4XY, UK

C N Martyn

$M$ Cruddas

University of

Cambridge Clinical

School, Neurology

Department,

Addenbrooke's

Hospital, Cambridge

CB2 2QQ, UK

D A S Compston

Correspondence to:

Dr Martyn

Received 30 January 1992 and in revised form 6 May 1992.

Accepted 27 May 1992

\section{Methods} published elsewhere. ${ }^{4}$ In brief, 225 patients with acute episodes of optic neuritis $(n=64)$, isolated demyelinating lesions $(n=56)$ or clinically definite multiple sclerosis $(n=105)$ attending the National Hospitals for Nervous Diseases, Queen Square and Maida Vale or the Moorfields Eye Hospital were compared with two groups of controls: 98 HLA DR2 positive normal subjects selected from voluntary blood donors and 66 patients with neurological diseases (other than multiple sclerosis) attending the same hospitals. Information about past administered by a single interviewer. At the early childhood is usually mild or asympto-

time of the interview a sample of venous blood was taken for serological tests to identify antibodies against common viruses. An indirect fluorescent antibody technique specific for viral capsid antigen was used to detect EpsteinBarr virus seropositivity.

Statistical analysis was carried out using logistic regression with the EGRET statistical package. Information was incomplete for 11 cases and 4 controls and they were therefore excluded. No differences were found between the two control groups in the prevalence of seropositivity for Epstein-Barr virus or their experience of symptomatic infection and they were combined for statistical analysis. Results are summarised in the table as odds ratios with corresponding $95 \%$ confidence intervals. These odds ratios were calculated with age, sex and HLA DR2 status simultaneously present in the regression model.

\section{Results}

There was a statistically significant $(p=0.03)$ association between multiple sclerosis and recall of an illness diagnosed as infectious mononucleosis or glandular fever in subjects seropositive for Epstein-Barr virus when compared with those who were both seronegative and unable to recall such an illness (odds ratio $=2 \cdot 9: 95 \% \mathrm{CI} 1 \cdot 1$ to $7 \cdot 2$ ). The association was strongest $(p=0.01)$ in those who recalled having had infectious mononucleosis at or before the age of 17 years-the median age of infection in this group (odds ratio $=7 \cdot 9: 95 \%$ CI 1.7 to $37 \cdot 9$ ). There was no statistically significant increase in relative risk of multiple sclerosis in subjects seropositive to EpsteinBarr virus but who could not recall symptoms of infectious mononucleosis. Numbers are too small to allow any comment upon the relative risk of multiple sclerosis in subjects who reported an episode of infectious mononucleo-

Details of the design of the study have been infections was obtained using a questionnaire

\section{Discussion}

These findings confirm the results of the earlier case-control study ${ }^{3}$ and support an interpretation that multiple sclerosis is associated not with infection by Epstein-Barr virus per se but with delayed infection with the virus. This 
Table Relative risk (as estimated by the odds ratio) for multiple sclerosis associated with recall of infectious mononucleosis and seropositivity to Epstein-Barr virus capsid antigen (EBV-VCA). ( ${ }_{17} 17$ years was the median age of infection)

\begin{tabular}{llllll}
\hline Serology to & $\begin{array}{l}\text { Reported episode of } \\
\text { infectious mononucleosis }\end{array}$ & $\begin{array}{l}\text { Number of } \\
\text { controls }\end{array}$ & $\begin{array}{l}\text { Number of } \\
\text { cases }\end{array}$ & Odds ratio & $95 \%$ CI \\
\hline- & no & 42 & 41 & 1 & $1 \cdot 9$ \\
- & yes & 2 & 3 & $1 \cdot 4$ & $0 \cdot 3-12 \cdot 2$ \\
+ & no & 108 & 146 & $0 \cdot 8-2 \cdot 2$ \\
+ & yes (all ages) & 8 & 24 & $1 \cdot 1-7 \cdot 2$ \\
+ & yes (at age $\leq 17 \mathrm{yrs})^{\star}$ & 2 & 16 & $7 \cdot 9$ & $1 \cdot 7-37 \cdot 9$ \\
\hline
\end{tabular}

relation does not necessarily imply any aetiological connection between the two conditions but the strength of the association, particularly with symptomatic Epstein-Barr viral infection in the few years following puberty, and its specificity suggest that the possibility should not be discounted.

These results depend largely on subject recall. Could they be biased because cases tended to report past infection more fully than controls? Neither the subjects nor the interviewer had any previous expectation of an association between Epstein-Barr virus and multiple sclerosis. Furthermore, the fact that the association is specific for Epstein-Barr virus indicates that there was no general tendency for cases to report delayed viral infection more frequently than controls. We think that recall bias is unlikely to be the explanation for these findings but the possibility cannot be excluded. The study needs to be replicated using information from a source free from the possibility of this type of bias.

It has been pointed out that a link between delayed infection with Epstein-Barr virus and the development of multiple sclerosis is compatible with many unusual epidemiological features of the disease. ${ }^{56}$ In developing countries, where multiple sclerosis is rare, early infection with Epstein-Barr virus is almost universal. By contrast, in those areas of the world in which infectious mononucleosis is common and where, by implication, first exposure to Epstein-Barr virus is often delayed beyond the early years of childhood (Australia, Canada, many European countries, New Zealand, Scandinavian countries and the United States) the prevalence of multiple sclerosis is high. Further, the age-specific incidence curves for infectious mononucleosis and multiple sclerosis are similar; the peak of the curve for infectious mononucleosis precedes the peak of the curve for multiple sclerosis by a few years. It is interesting that clustering of places of residence of multiple sclerosis patients at age 13-20 years, with peak clustering at age 18 years, has recently been reported in a Norwegian population. ${ }^{7}$ As the authors pointed out, this finding is compatible with the idea that Epstein-Barr virus or a similar latent virus is a causal agent in multiple sclerosis. A relation between multiple sclerosis and delayed exposure to Epstein-Barr virus could also account for the observation that migrants from areas where multiple sclerosis is uncommon tend to retain a low risk of disease while those moving in early life from areas where the prevalence of multiple sclerosis is high, experience a reduction in risk.

1 Evans AS. New discoveries in infectious mononucleosis. Mod Med 1974;1:18-24.

2 Evans AS, Niederman JC. Epstein-Barr virus. In: Alfred S, Evans AS, eds: Viral infection of humans: epidemiology and control 3rd Ed. New York: Plenum, 1989.

3 Operskalski EA, Visscher BR, Malmgren R, Detels R. A case-control study of multiple sclerosis. Neurology 1989; 39:825-9.

4 Compston DAS, Vakarelis BN, Paul E, McDonald WI, Batchelor JR, Mims CA. Viral infection in patients with multiple sclerosis and HLA-DR matched controls. Brain 1986;109:325-44.

5 Warner HB, Carp RI. Multiple sclerosis and Epstein-Barr virus. Lancet $1981 ; \mathbf{i i}: 1290$.

6 Martyn CN. The epidemiology of multiple sclerosis. In: Matthews WB, ed. McAlpine's multiple sclerosis. Edinburgh: Churchill Livingstone, 1991.

7 Rise T, Grønning M, Klauber MR, Barrett-Connor E, Nyland $\mathrm{H}$, Albrektsen $\mathrm{G}$. Clustering of residence of multiple sclerosis patients at age 13-20 years in Hondaland, Norway. Am $\mathcal{F}$ Epidemiol 1991;133:932-9. 